\title{
Aerodynamic Characteristics of Voice Disorders (Polyp, Cyst) before and after Laryngeal Micro Surgery: Focus on Running Speech
}

\author{
Tae-Hoon Moon (D, Mi-Ran Shim (D), Yeon-Shin Hwang (D), \\ Geun-Jeon Kim (D), Dong-Hyeon Lee (iD, and Dong-II Sun (D)
}

Department of Otorhinolaryngology-Head and Neck Surgery, Seoul St. Mary's Hospital, The Catholic University College of Medicine, Seoul, Korea

\author{
성대폴립, 성대낭종 환자들의 Laryngeal Micro Surgery 수술 전, 후 공기역학적 비교: \\ Running Speech 중심으로
}

문태훈, 심미란, 황연신, 김근전, 이동현, 선동일

가톨릭대학교 의과대학 서울성모병원 이비인후과학교실

Background and Objectives For patients with polyps and cysts, glottal gaps resulting from their lesions have negative respiratory effects when they vocalize. Phonatory Aerodynamic System is clinically used, but is often limited in the measurement of vowels. So the researchers attempted to verify the usefulness of Phonatory Aerodynamic System by comparing differences in respiratory characteristics and patterns which can be measured by the level of connected speech.

Materials and Method Among the subjects who were diagnosed through a stroboscopy, there were 33 patients with polyps and 23 patients with cysts. Then, 36 subjects who were found to have no specific findings through a stroboscopy and perceptual test were selected to the normal group. We compared respiratory characteristics and patterns. And compared vocal polyps and cysts before and after laryngeal micro surgery (LMS).

Results First, difference in respiratory patterns between the normal group and the patients with polyps and cysts were examined to show that breath groups, breath group syllables, and expiratory - inspiratory volume were significantly higher in the polyp/cyst group than those in the normal group, indicating that precision was lowered during the conversation, due to reduction in speech intelligibility and interruption of communication. Second, there were significant differences in maximum phonation time, mean flow rate, and subglottal pressure among respiratory characteristics, breath groups, breath group syllables, and inspiratory volume before and after LMS, which appeared to be similar to the normal group.

Conclusion The understanding of respiratory characteristics and patterns produced by patients in connected speech which is most similar to natural speech was found to be the objective and useful method for examining characteristics of the subjects.

Keywords Vocal cord; Polyp; Cyst.

\author{
Received March 26, 2019 \\ Revised May 13, 2019 \\ Accepted June 25, 2019
}

Corresponding Author

Dong-ll Sun, PhD

Department of Otorhinolaryngology-

Head and Neck Surgery,

Seoul St. Mary's Hospital,

The Catholic University College of Medicine,

222 Banpo-daero, Seocho-gu,

Seoul 06591, Korea

Tel $+82-2-2258-6212$

Fax+82-2-2258-1378

E-mail hnsdi@catholic.ac.kr

\section{ORCID iDs}

Tae-Hoon Moon (iD

https://orcid.org/0000-0002-6389-1512 Mi-Ran Shim (D)

https://orcid.org/0000-0001-9105-7237

Yeon-Shin Hwang (DD

https://orcid.org/0000-0001-6914-0149 Geun-Jeon Kim (D)

https://orcid.org/0000-0002-5032-5853

Dong-Hyeon Lee (D)

https://orcid.org/0000-0003-4049-2823

Dong-II Sun (D)

https://orcid.org/0000-0001-9950-568X

This is an Open Access article distributed under the terms of the Creative Commons Attribution Non-Commercial License (https://creativecommons.org/ licenses/by-nc/4.0) which permits unrestricted non-commercial use, distribution, and reproduction in any medium, provided the original work is properly cited. 


\section{서 론}

정상적인 음성이 산출되기 위해서는 말소리 메커니즘 호흡, 발성, 공명, 조음이 적절하게 상호작용하는 것이 중요하다. 호 흡은 발성을 위한 첫 단계이며 성대를 진동시키기 위한 에너 지원이 된다. ${ }^{1)}$ 이처럼 호흡과 발성은 복잡한 협응으로 이루어 지며 호흡과 발성, 후두의 밸브작용과 관련된 메커니즘을 평 가하여 발성의 특징도 알 수 있고 정상음성과 음성장애를 진 단할 수 있다.

이런 양성병변 음성장애 환자들은 성대병변으로 인해 비정 상적인 틈이 생기게 되어 발성 시 호흡특성에 악영향을 주게 되어 다양한 음성 검사와 함께 호흡 검사가 요구된다. 현재 임 상에서 주로 사용되는 호흡 검사로는 Phonatory Aerodynamic System(PAS, Model No.6600, KayPENTAX Corp., Lincoln Park, NJ, USA)이 있으며 주로 음절 수준과 단모음을 이용하여 화자의 호흡과 발성의 메커니즘을 평가하게 된다. 하 지만 최근 기존 검사들의 경우 음절 수준에서 진행되고 있으 며 이는 자연스러운 발화가 아니라는 한계점으로 인해 연속발 화에 대한 연구가 주목되고 있으며 이에 최근 음향학적 검사 에서도 analysis of dysphonia in speech and voice, linear predicative coding 같이 연속발화 상황에서의 검사가 활발 하게 진행되는 실정이다. 그러나 이에 비해 연속발화 상황에 서 호흡과 관련된 연구는 드문 실정으로 본 연구자는 연속발 화에서의 호흡단락 및 호흡패턴을 주목하게 되었다.

연속발화 상황에서는 빠른 흡기와 점진적(gradual)인 호기 가 통제된 상태에서 균형 있게 이루어지는 호흡단락(breath group)이 생기게 되고 ${ }^{2}$ 호흡단락은 휴지(pause)를 통해 구분 되며 호흡조절을 보여주는 것뿐만 아니라 의사소통에 있어서 의미를 구분해주는 역할을 하기 때문에 중요하다. ${ }^{3)}$

호흡단락이 적절히 조절되지 못할 경우에는 부적절한 휴지 로 인하여 말명료도(speech intelligibility)를 저하시키는 주요 원인이 되며, 적절한 휴지는 구문론적 경계(syntactic boundary)에서 나타나야 청자가 듣고 화자의 의도를 파악하는 데 중요한 역할을 하게 된다. ${ }^{4)}$

호흡단락을 구분하는 휴지의 구분은 대체로 청지각적, 음 향학적, 생리적 방법에 의해 수행된다. ${ }^{4)}$ 청지각적 방법은 화 자의 말소리를 듣고 흡기가 이루어진 시점을 주관적으로 판 단한 방법이며, 음향학적인 방법은 말소리를 음향학적으로 분석하여 파형(waveform)을 보고 판단하는 방법, 생리적 방 법은 눈으로 관찰되는 신체 부위의 변화(흥곽의 변화)와 구 강 기류의 측정을 통해 파악할 수 있다. ${ }^{3)}$

따라서 본 연구자는 생리적 측정 방법을 사용한 PAS 프로 토콜 중 running speech를 통해 현재 임상에서 사용되고 있는
공기역학적 검사의 한계점인 음절 수준에서의 검사가 아닌, 연 속발화 상황에서의 정상 화자, 양성병변 화자의 호흡특성을 살펴보고, 이후 후두미세수술(laryngeal micro surgery, LMS) 전/후 연속발화에서 호흡특성을 비교하여 효과적이며 효율 적인 평가를 할 수 있는 기초 자료를 제공하고자 하였다.

\section{대상 및 방법}

\section{연구 대상}

대상자는 2018년 3 7월까지 서울성모병원 이비인후과에 내 원하여 후두내시경을 통해 이비인후과 전문의에 의해 성대폴 립, 성대낭종으로 진단받고 후두미세수술이 예정된 대상자로 성대폴립 33명, 성대낭종 23명을 선정하였다. 정상 그룹은 음 성장애의 평가 및 치료 경력이 10년 이상인 숙련된 음성치료 전 문가 2명이 grade, rough, breathy, asthenic, strained(GRBAS) 척도를 통해 평정치가 0 (정상)으로 판단되었으며 후두내시경 을 통해 특이소견이 없는 36명을 선정하였다. 이들은 후두내 시경을 통해 전문의에게 급성 후두염, 역류성 식도염, 알레르 기 비염을 진단받지 않았으며 다른 말-언어 산출에 어려움을 보이지 않는 대상자로 선정하였다. 세 그룹 간 성별, 연령에는 유 의한 차이를 보이지 않았으며 호흡단락의 특성은 체형(body type)에 영향을 받지 않아 고려하지 않았다. ${ }^{5)}$ 본 연구는 서울 성모병원 임상시험심사위원회의 검토와 승인을 받았고 모든 환자의 동의하에 진행되었다(No. KC19RESI0248).

\section{녹음 및 검사 방법}

호흡 검사는 PAS를 사용하여 진행하였다.

호흡특성 검사로는 최대연장 발성시간(maximum phonation time, MPT), 평균호기류율(mean flow rate, MFR), 성문 하압(subglottal pressure, Psub), 음성효율(voice efficiency) 을 측정하였다.

최대연장 발성시간(MPT, 단위: sec)은 최대한 공기를 들이 마시고 편안한 음으로 '아'를 최대한 길게 발성하도록 유도하 였다. 총 3회 반복 측정을 통해 가장 길게 발성한 값을 선택하 였다. 평균호기류율(MFR, 단위: $\mathrm{mL} / \mathrm{sec}$ )은 최대연장 발성시 간 측정 중 안정된 구간 5 초를 설정하여 값을 선택하였다. 성 문하압(Psub, 단위: $\mathrm{cm} \mathrm{H}_{2} \mathrm{O}$ )은 입술과 입술 사이에 튜브를 위치시키고 편안한 음으로 '파를 5번 유도한 뒤 3회 반복 측정 하였다. 이 중 두 번째 실시한 '파' 중 맨 앞과 맨 뒤의 '파'를 제 외한 가운데 '파'를 측정한 값을 선택하였다

호흡패턴을 검사하기 위해 '산책' 문단을 사용하였으며 연 속발화 수준의 검사를 위해 약 35초 분량의 '산책' 문단 중 일 부를 이용하였다. '산책' 문단은 휴지에 대한 단서를 제공해 줄 
수 있는 문단이기 때문에 일부를 사용하였으며 아래 내용은 연구에 사용된 '산책' 문단을 제시한 것이다.

높은 산에 올라가 맑은 공기를 마시며 소리를 지르면 가슴이 활짝 열리는 듯하다. 바닷가에 나가 조개를 주으며 넓게 펼쳐있 는 바다를 바라보면 내 마음 역시 넓어지는 것 같다. 가로수 길게 뻗어 있는 곧은길을 따라 걸어가면서 마치 쭉쭉 뻗어 있는 나무 들처럼, 그리고 반듯하게 놓여 있는 길처럼 바른 마음으로 자연 을 벗하며 살아야겠다는 생각을 한다.

대상자들은 검사하기 전 검사 방법 및 내용을 숙지하였으 며 호흡패턴 검사 시 읽기 오류를 방지하기 위해 '산책' 문단 을 2 번 반복하여 읽은 후 실시하였다. 성대폴립, 성대낭종 그 룹의 경우 수술 전 running speech를 통해 호흡패턴을 측정 한 후 LMS 수술을 통해 성대병변을 제거한 뒤 평균 4주 동 안 음성휴식 기간을 거친 후 다시 방문하여 동일한 검사를 실 시하였다.

호흡패턴 검사로는 호흡단락(breathy group), 호흡단락 당 음절수(breathy group syllable), 총 지속시간(phonation time), 호기· 흡기 지속시간(expiratory · inspiratory airflow duration), 총 호기·흡기 용량(expiratory · inspiratory volume), 호 기·흡기 최대값(peak expiratory·inspiratory airflow)을 측 정하였다.

호흡단락은 발화 시작을 위해 호기를 시작한 지점부터 다 음 발화를 위해 흡기가 시작된 지점 또는 호기가 끝난 지점을
하나의 호흡단락으로 정의하였다. ${ }^{3)}$

호흡단락당 음절수는 총 음절수에 호흡단락이 나타난 갯 수를 나누어 하나의 호흡단락에서 나타나는 평균 음절수를 측정하였다. Fig. 1 은 호흡단락과 호흡단락당 음절수를 측정 하는 방법을 제시한 것이다.

총 지속시간은 '산책' 문단을 낭독하는 데 걸린 시간, 호기 지속시간(expiratory airflow duration), 흡기지속시간(inspiratory airflow duration)은 호기와 흡기가 지속된 시간을 나 타낸다. 총 호기 용량(expiratory volume)과 총 흡기 용량(inspiratory volume)은 낭독 시 얼마만큼의 호흡의 양을 사용하 였는지를 볼 수 있는 파라미터 수치들이다. 호기·흡기 최대값 (peak expiratory· inspiratory airflow)은 최고점을 찍은 흡 기·호기값을 나타낸 수치들이다.

이러한 파라미터들은 running speech 프로토콜을 통해 자 동적으로 계산되어지며 Table 1은 그 결과값을 제시한 것이다.

\section{자료 분석}

Running speech 프로토콜은 음도(pitch), 음압(sound pressure), 기류량(airflow) 변화 양상이 실시간으로 화면에 제시 된다. 기류량 변화를 통해 호기와 흡기가 일어나는 시점을 구 분할 수 있다. 0 을 기준으로 +값은 호기량, -값은 흡기량이며 이러한 값들은 직접 계산하지 않고 파라미터 수치로 제공되 어 진다. 이러한 파라미터들을 통해 연속발화 상황에서의 호 흡패턴을 살펴보았다.

따라서 본 연구자는 비교를 위해 우선 정상 그룹과 성대폴

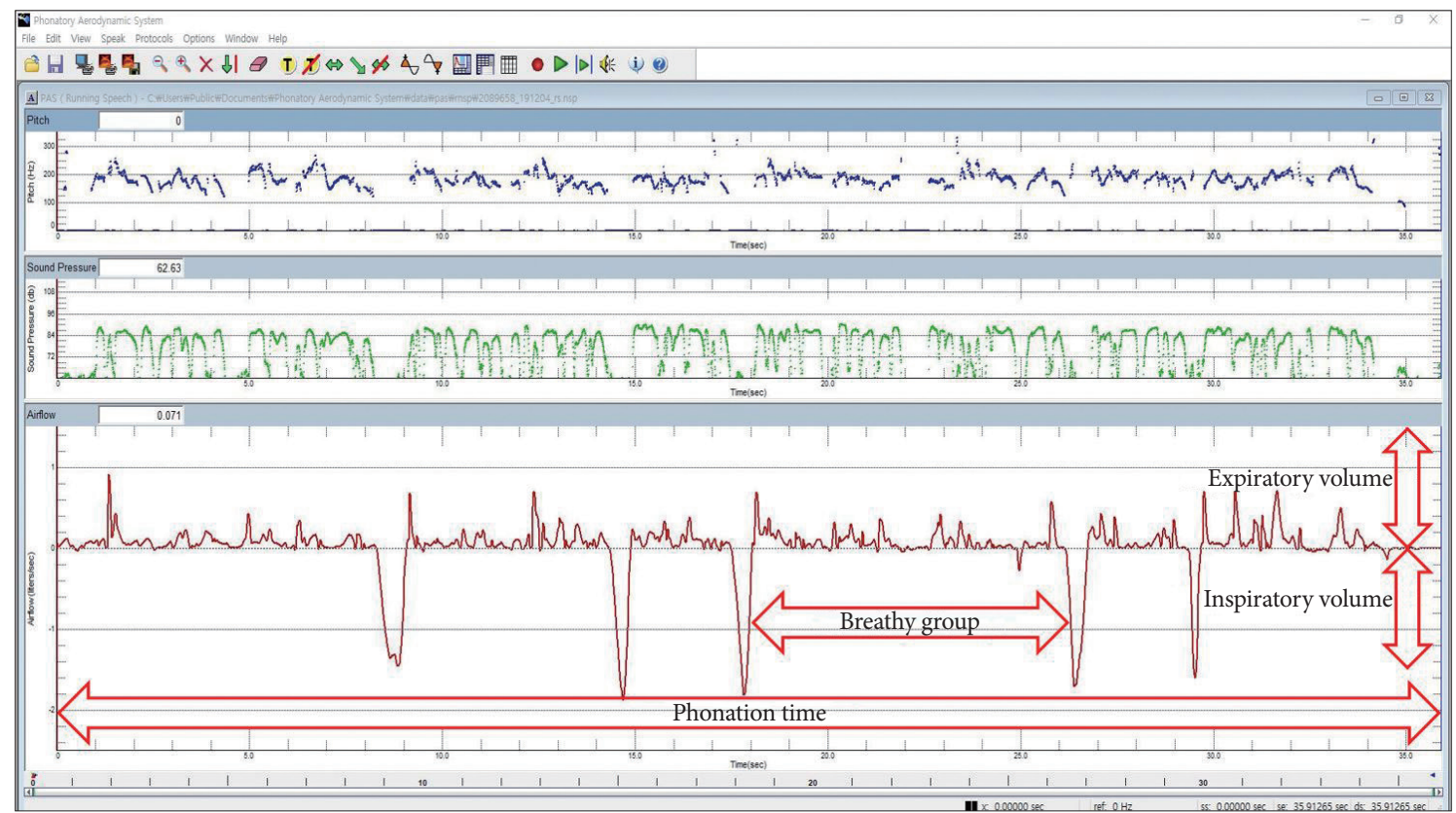

Fig. 1. Running speech protocol in Phonatory Aerodynamic System. 
립, 성대낭종 그룹의 호흡특성을 비교하여 차이를 알아보았으 며, LMS 수술 전/후 성대폴립과 성대낭종 그룹의 호흡특성 및 호흡패턴의 차이를 비교하였다.

\section{통계 분석}

통계는 SPSS 21.0(IBM Corp., Armonk, NY, USA)을 사용 하였다. 정상 그룹, 성대폴립, 성대낭종 그룹의 평균 유의한 차 이를 보이는지 알아보기 위해 일원분산분석(one-way analysis of variance)을 사용하였고 어떠한 그룹에서 유의한 차이 를 나타났는지를 살펴보기 위해 투키-사후 검정(Tukey posthoc)을 실시하였다. 그리고 성대폴립, 성대낭종 그룹의 LMS 전/후 호흡특성, 호흡패턴을 비교하기 위하여 대응표본 $\mathrm{t}$-검 정(paried t-test)을 사용하여 분석하였다.

Table 1. Running speech result in Phonatory Aerodynamic System

\begin{tabular}{|lr|}
\hline \multicolumn{1}{|c}{ Running speech parameter } & Result \\
\hline Maximum SPL, dB & 81.81 \\
\hline Mean pitch, $\mathrm{Hz}$ & 171.64 \\
\hline Pitch range, $\mathrm{Hz}$ & 199.21 \\
\hline Phonation time, sec & 17.02 \\
\hline Expiratory airflow duration, sec & 21.91 \\
\hline Inspiratory airflow duration, sec & 4.91 \\
\hline Peak expiratory airflow, L/sec & 0.70 \\
\hline Expiratory volume, $\mathrm{L}$ & 3.13 \\
\hline Peak inspiratory airflow, L/sec & -1.64 \\
\hline Inspiratory volume, $\mathrm{L}$ & -2.36 \\
\hline
\end{tabular}

SPL: sound pressure level

Table 2. Comparison of respiratory characteristics of three groups

\begin{tabular}{lcccc}
\multicolumn{1}{c}{ Respiratory characteristics } & Normal $(\mathrm{n}=36)$ & Polyp $(\mathrm{n}=33)$ & Cyst $(\mathrm{n}=23)$ & $\mathrm{p}$-value \\
Maximum phonation time, $\mathrm{sec}$ & $20.77 \pm 2.85$ & $12.28 \pm 3.52$ & $11.53 \pm 3.21$ & $<0.010$ \\
Mean flow rate, $\mathrm{mL} / \mathrm{sec}$ & $95.27 \pm 28.63$ & $145.44 \pm 30.55$ & $182.17 \pm 20.21$ & 0.001 \\
Subglottal pressure, $\mathrm{cm} \mathrm{H} \mathrm{H}_{2} \mathrm{O}$ & $6.62 \pm 1.26$ & $11.69 \pm 3.12$ & $11.93 \pm 2.80$ & $<0.010$ \\
Vocal efficiency & $112.69 \pm 201.22$ & $70.08 \pm 107.55$ & $120.52 \pm 307.51$ & 0.392 \\
\hline Variables are presented as mean & & &
\end{tabular}

Variables are presented as mean \pm standard deviation

Table 3. Comparison of running speech of three groups

\begin{tabular}{lcccc}
\multicolumn{1}{c}{ Running speech } & Normal $(\mathrm{n}=36)$ & Polyp $(\mathrm{n}=33)$ & Cyst $(\mathrm{n}=23)$ & $\mathrm{p}$-value \\
Breath group & 7.36 & 10.90 & 10.56 & $<0.010$ \\
Breath group syllable & 20.22 & 14.31 & 15.27 & $<0.010$ \\
phonation time, sec & 20.09 & 21.30 & 21.39 & 0.344 \\
Expiratory airflow duration, sec & 24.79 & 27.05 & 26.28 & 0.076 \\
Inspiratory airflow duration, sec & 6.33 & 7.48 & 7.22 & 0.276 \\
Peak expiratory, L & 1.90 & 0.96 & 1.06 & 0.650 \\
Expiratory volume, L & 2.66 & 4.70 & 5.20 & $<0.010$ \\
Peak inspiratory, L & -1.61 & -1.64 & -1.86 & 0.320 \\
Inspiratory volume, L & -2.73 & -4.37 & -4.82 & $<0.050$ \\
\hline
\end{tabular}

Variables are presented as mean

\section{결 과 \\ 정상 그룹과 성대폴립, 성대낭종 그룹 비교}

정상 그룹과 성대폴립, 성대낭종 그룹 간 호흡특성 결과

정상 그룹과 성대폴립, 성대낭종 그룹 간 최대연장 발성시간 (MPT), 평균호기류율(MFR), 성문하압(Psub)에서 유의한 차 이를 보여 정상 그룹보다 비정상적인 성문 틈으로 인해 기류 손실이 나타나 기식성 음성을 산출하는 것으로 나타났다 $(\mathrm{p}<$ 0.01)(Table 2).

투키-사후 검정 결과 정상-성대폴립, 정상-성대낭종 그룹 에서 유의한 차이를 보였으며 $(\mathrm{p}<0.01)$ 성대폴립-성대낭종에 서는 유의한 차이를 보이지 않았다( $\mathrm{p}>0.05)$.

\section{정상 그룹과 성대폴립, 성대낭종 그룹 간 running speech 호흡패턴 결과}

정상 그룹과 성대폴립, 성대낭종 그룹 간 호흡단락, 호흡단 락당 음절수, 총 호기 용량, 총 흡기 용량에서 유의한 차이를 보여 부적절한 휴지와 정상 그룹보다 더 많은 용량의 공기가 필요한 것으로 나타났다 $(\mathrm{p}<0.01)$ (Table 3$)$.

투키-사후 검정 결과 정상-폴립, 정상-낭종 그룹에서 유의 한 차이를 보였으며 $(\mathrm{p}<0.01)$ 폴립-낭종에서는 유의한 차이를 보이지 않았다 $(\mathrm{p}>0.05)$. 


\section{성대폴립과 성대낭종 LMS 수술 전/후 비교}

성대폴립과 성대낭종 LMS 수술 전/후 호흡특성 결과

$\mathrm{LMS}$ 수술 전/후 최대연장 발성시간, 호기류율, 성문하압에 서 유의한 차이를 보였으며 기식음 없이 정상 수치에 유사한 결과값을 보였다 $(\mathrm{p}<0.05, \mathrm{p}<0.01)$ (Table 4).

\section{성대폴립과 성대낭종 LMS 수술 전/후 running speech} 결과

LMS 수술 전/후 호흡단락, 호흡단락당 음절수, 호기 총량 에서 유의한 차이를 보여 정상 그룹 수치와 유사한 결과 값으 로 나타났다 $(\mathrm{p}<0.05, \mathrm{p}<0.01)$ (Table 5).

\section{고 찰}

본 연구는 음성장애 환자의 수술 전·후 호흡특성을 새로 운 파라미터를 통해 살펴보고자 하였다. 그 결과, 정상 그룹과 성대폴립, 성대낭종 그룹의 수술 전 기존 파라미터인 최대연 장 발성시간, 호기류율, 성문하압에서 기존의 선행 연구와 동 일하게 유의한 차이를 보였으며, running speech를 이용한 새로운 파라미터들에서는 호흡단락, 호흡단락당 음절수, 흡 기 총량, 호기 총량에서 유의한 차이를 보였다.

본 연구에 참여한 참여자들은 성대폴립, 성대낭종 수술이 예정된 환자로 발화 시 성대폐쇄부전을 동반한 환자들이었다.
따라서 정상 그룹에 비해 유의한 차이를 보이는 호흡특성을 보였다. 성대폐쇄부전으로 인해 기류 손실이 많아 평균 호기 류율은 상승하게 되며 최대연장 발성시간과 성대를 통과하여 나오는 기류인 성문하압은 감소하게 되는 특징을 보이게 된 다.) 반면 본 연구에서는 성대폴립, 성대낭종 환자들이 정상 그룹에 비해 높은 성문하압을 보였다. 이는 성대폴립, 성대낭 종 환자들이 부적절한 호흡과 발성을 보완하기 위해 성대를 평상시에 사용하는 것보다 강한 강도나 음도로 사용하여 ${ }^{7)}$ 높 은 성문하압과 증가된 기류 속도로 성문폐쇄기의 비율을 크게 만들어 성대 과내전을 발생시키는 보상 전략의 특성으로 생각 된다. ${ }^{8)}$

LMS 수술 전/후 호흡특성에서 최대연장 발성시간, 평균 호 기류율, 성문하압에서 유의한 차이를 보였다. 수술 후 증가된 최대연장 발성시간, 감소된 평균 호기류율, 성문하압을 보이게 되었다. 성문하압의 경우 높게 측정되는 성대폴립, 성대낭종 그룹 모두 수술 전 정상 범주에 벗어났다. 성대폴립, 성대낭종 그룹은 병변으로 인해 성대접촉이 감소되면서 음성을 산출하 기 위해 높은 성문하압을 사용하게 되는 보상 작용이 나타나게 되는데 이는 선행 연구와 동일한 결과로 해석될 수 있다. ${ }^{8}$

LMS 수술 전/후에서 호흡단락, 호흡단락당 음절수, 흡기· 호기 총량에서 유의한 차이를 보였는데 부적절한 휴지가 나 타나게 된다면 말명료도(speech intelligibility)를 저하시키게 되는 요인이 된다. 이는 성공적인 의사소통을 위해서는 호흡 이 적절히 조절되지 못하는 원인으로 볼 수 있었다. 또한 휴지

Table 4. Comparison respiratory characteristics of pre/post laryngeal micro surgery

\begin{tabular}{|c|c|c|c|c|c|c|}
\hline \multirow{2}{*}{ Respiratory characteristics } & \multicolumn{3}{|c|}{ Polyp $(n=17)$} & \multicolumn{3}{|c|}{ Cyst $(n=17)$} \\
\hline & Pre & Post & p value & Pre & Post & p value \\
\hline Maximum phonation time, sec & 11.04 & 14.46 & $0.001^{* *}$ & 11.90 & 18.24 & $0.002^{* *}$ \\
\hline Mean flow rate, $\mathrm{mL} / \mathrm{sec}$ & 145.29 & 113.52 & $0.040^{*}$ & 204.11 & 113.67 & $0.001^{* *}$ \\
\hline Subglottal pressure, $\mathrm{cm} \mathrm{H}_{2} \mathrm{O}$ & 11.57 & 8.40 & $0.000^{* *}$ & 12.34 & 9.12 & $0.000^{* *}$ \\
\hline Vocal efficiency & 103.96 & 100.65 & 0.934 & 122.89 & 82.61 & 0.520 \\
\hline
\end{tabular}

Variables are presented as mean. ${ }^{*} \mathrm{p}<0.05,{ }^{* *} \mathrm{p}<0.01$

Table 5. Comparison of running speech of pre/post laryngeal micro surgery

\begin{tabular}{|c|c|c|c|c|c|c|}
\hline \multirow{2}{*}{ Running speech } & \multicolumn{3}{|c|}{ Polyp $(n=17)$} & \multicolumn{3}{|c|}{ Cyst $(n=17)$} \\
\hline & Pre & Post & $p$ value & $\overline{\text { Pre }}$ & Post & $\overline{p \text { value }}$ \\
\hline Breath group & 12.13 & 9.13 & $0.008^{* *}$ & 10.29 & 8.41 & $0.037^{*}$ \\
\hline Breath group syllable & 12.59 & 16.38 & $0.009^{* *}$ & 14.90 & 17.65 & $0.045^{*}$ \\
\hline phonation time, sec & 20.82 & 20.59 & 0.827 & 21.33 & 20.06 & 0.134 \\
\hline Expiratory airflow duration, sec & 26.40 & 25.81 & 0.608 & 26.17 & 26.07 & 0.916 \\
\hline Inspiratory airflow duration, sec & 6.96 & 6.47 & 0.429 & 6.82 & 7.07 & 0.593 \\
\hline Peak expiratory, L & 0.08 & 0.60 & 0.110 & 1.11 & 0.88 & 0.076 \\
\hline Expiratory volume, $\mathrm{L}$ & 3.98 & 2.64 & $0.048^{*}$ & 5.58 & 4.08 & $0.049^{*}$ \\
\hline Peak inspiratory, L & -1.64 & -1.47 & 0.258 & -2.00 & -1.68 & 0.123 \\
\hline Inspiratory volume, $\mathrm{L}$ & -3.87 & -2.48 & 0.104 & -4.91 & -4.41 & 0.437 \\
\hline
\end{tabular}

Variables are presented as mean. ${ }^{*} \mathrm{p}<0.05,{ }^{* *} \mathrm{p}<0.01$ 
는 구문론적 경계(syntactic boundary)에서 나타나야 청자가 듣고 의미적으로 화자의 의도를 파악하는 데 큰 역할을 하게 되는데 호흡단락수 및 호흡단락당 음절수가 정상과 유의한 차 이를 보이는 것은 성대의 양성병변으로 인하여 화자의 말명 료도 및 의사전달을 방해하며 대화 상황에서의 정확성을 저 하시키는 원인으로 볼 수 있다. 이는 양성병변 환자들이 수술 전 음성장애지수(Voice Handicap Index) 중 기능적 영역에 대한 항목에서 높은 점수를 보이는 것과 관계가 있는 것으로 생각된다.

수술 후 호흡단락, 호흡단락당 음절수에서 선행 연구 ${ }^{4}$ 에서 측정된 평균 음절 산출수 17.95 음절과 비슷한 음절수가 나 타나 후두미세 수술 후 정상적인 호흡단락 및 호흡단락수로 회복되는 것을 알 수 있었다. 또한 수술 후 호기 총량에서 유 의한 차이를 보였는데 이는 수술 후 발화 시 기류손실이 적어 져 적은 호기량으로 정상 그룹과 유사한 호흡특성을 보이는 것으로 생각된다.

그러나 본 연구에서는 성대의 근육의 부피가 줄어들고 탄 력도를 감소하게 되는 성대 노화를 고려하지 않았다." 연구 참 여자 중 여성의 비중이 높았으며 폐경기 후 성대 노화로 인하 여 호흡 기능과 호흡 문제가 발생한다고 보고하고 있으며 추 후 성대 노화가 진행되는 연령인 50세를 기준으로 그룹을 나 누어 연구를 진행하는 것을 제언한다. ${ }^{10,11}$ 또한 신경학적 음성 장애 환자군 중 호흡에 문제를 보이는 성대마비, 연축성 발성 장애(spasmodic dysphonia), 성문 틈(gap)을 보이는 환자들 을 포함하여 전반적인 호흡특성을 살펴보는 후속 연구가 이루 어져야 할 필요가 있다.

\section{결 론}

본 연구 결과에서 보듯이 성대폴립, 성대낭종 환자와 정상 그룹은 다른 호흡단락의 특성을 보였다. 연속발화 산출 시 호흡단락 횟수, 호흡단락당 음절수, 필요한 공기의 양, 소비 되는 공기의 양에서 다른 특성을 보여주었다. 이는 running speech 프로토콜을 이용하여 화자의 자연스러운 발화상황 과 가장 비슷한 연속발화 산출 시 특성을 파악하는 데 객관 적이고 유용한 방법임을 알 수 있었다.
중심 단어: 성대, 폴립, 낭종.

Acknowledgments

None.

Conflicts of Interest

The authors have no financial conflicts of interest.

Authors' Contribution

Conceptualization: Dong Il-Sun, Tae-Hoon Moon. Data curation: Tae-Hoon Moon, Yeon-Shin Hwang, Mi-Ran Sim, Geun-Jeon Kim, Dong-Hyeon Lee. Formal analysis: Tae-Hoon Moon. Investigation: Tae-Hoon Moon, Mi-Ran Sim, Geun-Jeon Kim. Methodology: TaeHoon Moon, Yeon-Shin Hwang, Dong-Hyeon Lee. Project administration: Dong-Il Sun. Supervision: Dong-Il Sun. Approval of final manuscript: all authors.

\section{REFERENCES}

1. Titze IR, Wong D, Milder MA, Hensley SR, Ramig LO. Comparison between clinician-assisted and fully automated procedures for obtaining a voice range profile. J Speech Hear Res 1995;38(3):526-35.

2. Wang YT, Nip IS, Green JR, Kent RD, Kent JF, Ullman C. Accuracy of perceptual and acoustic methods for the detection of inspiratory loci in spontaneous speech. Behav Res Methods 2012;44(4):1121-8.

3. Pyo HY, Kim SY, Baek SK. A comparison study of breath groups during reading paragraph tasks in normal adults and adult patients with voice disorders: a preliminary study. Phonetics and Speech Sciences 2014;6(4):181-7.

4. Han JY, Lee OB, Shim LS. The study of breath group based on oral airflow in reading by healthy speakers. Speech science 2008;15(4):135-46.

5. Manifold JA, Murdoch BE. Speech breathing in young adults: effect of body type. J Speech Hear Res 1993;36(4):657-71.

6. Seo JS, Song SY, Kwon OC, Kim JW, Lee HK, Jeong OR. Mean Value of Aerodynamic Study in Normal Korean. J Korean Laryngol Phonia 1997;8(1):27-32.

7. Kim JO. Aerodynamic characteristics, vocal efficiency, and closed quotient differences according to fundamental frequency fixation. Phonetics and Speech Sciences 2013;5(1):19-26.

8. Wang SG. Larynx examinations in otorhinolaryngology clinic about voice problems focusing on diagnosis \& evaluation of voice disorders. Cogito 2010;68(68):27-65.

9. Park IS. Histopathologic and physiologic features of the aging larynx. J Korean Laryngol Phonia 2014;25(1):20-3.

10. Songür N, Aydin ZD, Oztürk O, Sahin U, Khayri U, Bircan A, et al. Respiratory symptoms, pulmonary function, and reproductive history: isparta menopause and health study. J Womens Health (Larchmt) 2010;19(6):1145-54.

11. Benninger MS, Jacobson BH, Johnson AF. Vocal arts medicine: the care and prevention of professional voice disorders. New York, NY: Thieme Medical Publishers, Inc.;1994. 